Article

\title{
Design and Optimization of Laser Processing Control System and Process Parameters for Micro Crystal Resonator Frequency Modulation
}

\author{
Jian $\mathrm{Hu}^{1}{ }^{1}$, Sangdu Guo ${ }^{1}$, Bao Fang ${ }^{1}$, Xindong Yu ${ }^{2}$, Zhiqiang Gu ${ }^{1, *}$ and Gangyan Li ${ }^{1, * \mathbb{D}}$ \\ 1 School of Mechanical and Electronic Engineering, Wuhan University of Technology, 122 Luoshi Road, \\ Wuhan 430070, China; hujian@whut.edu.cn (J.H.); 259445@whut.edu.cn (S.G.); 259587@whut.edu.cn (B.F.) \\ 2 Key Laboratory of Hubei Province for MicroNano Crystal Processing Technology, Zengdu Economic \\ Development Zone, Suizhou 441300, China; yxd@sztkd.com \\ * Correspondence: gxkwhut@whut.edu.cn (Z.G.); gangyanli@whut.edu.cn (G.L.)
}

check for updates

Citation: Hu, J.; Guo, S.; Fang, B.; Yu,

X.; Gu, Z.; Li, G. Design and

Optimization of Laser Processing

Control System and Process

Parameters for Micro Crystal

Resonator Frequency Modulation.

Appl. Sci. 2022, 12, 2162. https://

doi.org/10.3390/app12042162

Academic Editors: Xuesong Mei,

Wenjun Wang and Jianlei Cui

Received: 14 December 2021

Accepted: 16 February 2022

Published: 18 February 2022

Publisher's Note: MDPI stays neutral with regard to jurisdictional claims in published maps and institutional affiliations.

Copyright: (C) 2022 by the authors. Licensee MDPI, Basel, Switzerland. This article is an open access article distributed under the terms and conditions of the Creative Commons Attribution (CC BY) license (https:/ / creativecommons.org/licenses/by/ $4.0 /)$.

\begin{abstract}
The adjustment of the natural frequency of a micro crystal resonator (MCR) is the key requirement in its manufacturing, which determines the actual performance of the product. Laser processing is a new method for MCR frequency modulation, and its process parameters directly affect the frequency modulation effect. Aiming at the laser processing equipment for MCR frequency modulation, the structure of the laser processing control system for MCR frequency modulation is designed by analyzing the requirements of a laser processing control system. The working flow of the laser processing control system for MCR frequency modulation is studied, the motion control method of the laser processing platform for MCR frequency modulation is proposed, and the laser processing control system for MCR frequency modulation is designed. By analyzing the laser characteristics for MCR frequency modulation, an orthogonal experiment is carried out to optimize the laser processing parameters for MCR frequency modulation.
\end{abstract}

Keywords: micro crystal resonator; laser processing; frequency modulation; control system; orthogonal experiment

\section{Introduction}

The micro crystal resonator (MCR) is an electronic device used to provide clock frequency for electronic products. It has the advantages of high frequency, small package size, high stability and low power consumption [1]. The commonly used MCR can be divided into tuning fork type and circular slice type. The frequency of the tuning fork type crystal resonator is $32.768 \mathrm{kHz}$ [2]. In the basic manufacturing process of the MCR, firstly, a quartz wafer is processed according to the required target frequency [3]. Secondly, the tuning fork electrode and circuit part of the MCR are produced. Thirdly, the frequency of the MCR is adjusted to near target frequency by changing the mass of the electrode. Finally, the frequency of the MCR is further adjusted to make its natural frequency reach the target value.

The main part of the MCR is a quartz wafer with silver coatings on the upper and lower sides as electrodes. The two electrodes are connected with the circuit through the lead. With both ends of the electrode having alternating electric fields, the wafer will be mechanically deformed and vibrated. When the voltage frequency is equal to the natural frequency of the MCR, piezoelectric resonance will occur to realize the conversion of electrical energy and mechanical energy.

According to the physical characteristics of the MCR, the surface silver layer on the MCR can be removed by laser so that the natural frequency of the MCR can be adjusted to achieve the desired target value. In the production process of the MCR, electrode area, density and shear elastic modulus are the inherent properties of quartz crystal. The original resonant frequency of the MCR is the original frequency of the MCR before frequency 
adjustment, and it is also a fixed value. Therefore, the frequency of the MCR can be changed by changing the mass of the MCR. When the mass of the silver layer is increased, the resonant frequency of the MCR decreases. When the mass of the silver layer is reduced, the resonant frequency of the MCR increases [4]. The laser processing system for MCR frequency modulation mainly includes the MCR carrier module, the frequency detection module and the laser processing module. In the process of laser frequency modulation, the wafer is transported to the processing position by the MCR carrier module. The frequency of the MCR is measured by the frequency detection module. According to the difference between the actual frequency and the target frequency of the MCR, the frequency of the MCR is adjusted by the laser processing module. A laser with a wavelength of $532 \mathrm{~nm}$ is used to thin the electrodes of the MCR with a fundamental frequency of $10 \mathrm{MHz}$ [4]. Laser irradiates the surface of the MCR to vaporize the silver layer. The thickness of the wafer is $0.8 \mathrm{~mm}$. The processing object is the $3225 \mathrm{MCR}(3.2 \times 2.5 \times 0.8 \mathrm{~mm})$ produced by TKD Science and Technology Co., Ltd in Suizhou, China.

In terms of frequency modulation technology, Shiono $\mathrm{T}$ et al. [5] designed the laser etching frequency adjustment and ion beam etching fine tuning technology to achieve the fine tuning of MCR frequency. Qiang Chen [6] developed ion etching equipment and designed an ion etching frequency modulation experiment in an inert gas environment. The frequency offset pattern after etching was obtained to optimize the ion etching process. Jingyu Shao [7] proposed and realized two laser etching methods, laser thinning and laser etching pattern, to finely tune the frequency of quartz crystal resonant devices. Qiang $\mathrm{Li}[8]$ used the laser marking machine and the corresponding electrical performance testing instrument to measure the frequency shifts of the crystal oscillator at different working currents and $Q$ pulse widths under frequency modulation and analyzed the change of the electrical performance parameters of the crystal oscillator after frequency modulation. In terms of the motion control method, Junejo $\mathrm{M}$ et al. [9] established a motor control model based on fuzzy PID control and simulated the control model to prove that the control method was successful. Ra A et al. [10] designed the simulation experiment of PID control and fuzzy PID control for the change of bed pressure rate. The analysis showed that the fuzzy PID controller has better effects in dynamic response. Khodadadi $\mathrm{H}$ et al. [11] designed a fuzzy PID controller for a disturbance observer of ball mill grinding, which can ensure the anti-interference movement of a ball mill. In terms of a micro-machining control system, Li Qiao [12] designed the control system of an integrated circuit parallel seam welder, combined with machine vision, and constructed the control interface with the C\# programming language. Xiaofeng $\mathrm{Xu}$ [13] used the motion control card to realize the motion control of the servo motor, used LabVIEW and MATLAB to construct the software control system and used the control idea of "trajectory discretization + interpolation motion + realtime feedback" to complete the control program of each functional module. Guohua Gao et al. [14] used LabVIEW to design a set of laser fine machining/monitoring system, used a micro-motion program and a position data acquisition program to compensate for errors and used machine vision technology to determine the processing defect area to improve the accuracy of laser processing. Richter $S$ et al. [15] proposed the laser etching method of a micro-heat pipe composite groove, designed an orthogonal experiment to explore the influence of laser parameters on groove etching effect and optimized the laser etching process parameters of a micro-heat pipe composite groove. Brügmann et al. [16] analyzed the temperature change in the process of continuous laser metal cutting by establishing a simulation model and studied the metal plate processing efficiency of different wavelengths of laser by process test. Aiming at the problem of laser etching of aluminum alloy sheet, Hui Zhang et al. [17] analyzed the effects of laser power, laser cutting speed and gas pressure on laser etching mass, established an orthogonal experiment based on a singlefactor experiment and obtained the process parameter combination with the best etching effect. According to the engineering application of a carbon dioxide laser in thick plate cutting, Ribu Li et al. [18] analyzed the quality evaluation index of thick plate laser cutting. Wei Zhang et al. [19] analyzed the laser cutting process of an Al-Li alloy, designed the 
orthogonal experiment based on the single-factor experimental results and optimized the process parameters by means of analysis of variance and signal-to-noise ratio analysis.

The MCR is a device made by using the resonance principle. When the frequency of the external electrical signal is equal to the natural frequency of the MCR, the MCR will resonate and realize the conversion between electrical energy and mechanical energy [20]. MCRs are mostly frequency-modulated individually, which makes them difficult to produce in large quantities. Few studies have been performed on large-range and high-precision carrier platforms and laser processing control systems for frequency modulation. Laser micromachining experiments are mostly carried out through laser cutting and laser welding. There are few experimental studies on the processing of micro-electronic products such as MCRs. The selection of laser control parameters in laser etching lacks theory. The laser processing control system for MCR frequency modulation realizes multi-objective MCR frequency modulation control and provides a reference for multi-objective micro-machining control of other electronic products. Optimization of process parameters for MCR frequency modulation provides a reference for laser micro-machining experiments and parameter selection of other electronic components.

In order to design the laser processing control system for MCR frequency modulation, optimize the process parameters and improve the frequency modulation qualification rate and processing efficiency of the MCR, the remaining contents of this paper are arranged as follows. In the first part, the overall scheme of the laser processing control system for MCR frequency modulation is designed by analyzing the principle, overall structure and performance requirements of laser processing frequency modulation. In the second part, the control process is designed and the control method is proposed. In the third part, the software and hardware of the control system are designed and the prototype is established and verified. In the fourth part, the process parameters of the control system are optimized by an orthogonal experiment and the optimized results are verified by experiments.

\section{Laser Processing Method and Control System Overall Scheme for MCR Frequency Modulation}

\subsection{Laser Processing Method for MCR Frequency Modulation}

The resonant frequency of the MCR is almost only related to the physical properties of the wafer itself. The Sauerbrey formula [7] describes the relationship between the change of resonant frequency and the mass change of the MCR:

$$
\Delta \mathrm{f}=\frac{-2 \Delta \mathrm{mf}_{0}^{2}}{\mathrm{~A} \sqrt{\rho_{\mathrm{q}} \mu_{\mathrm{q}}}}
$$

where $\Delta f$ is the frequency variation of the $\mathrm{MCR}, \mathrm{Hz} ; f_{0}$ is the original resonant frequency of the MCR, Hz; $\Delta m$ is the mass change of the MCR, $\mathrm{g} / \mathrm{cm}^{2} ; A$ is the electrode area of the $\mathrm{MCR}, \mathrm{cm}^{2} ; \rho_{q}$ is the density of quartz crystal, $\mathrm{g} / \mathrm{cm}^{3}$, and $\mu_{q}$ is the shear elastic modulus of quartz crystal, $P a$.

\subsection{Overall Structure of Laser Processing Control System for MCR Frequency Modulation}

The laser processing process for frequency modulation is briefly depicted in Figure 1. The MCR to be processed is placed on the working platform. The computer control system is used to control the pulse laser to produce the laser with appropriate energy density. After adjusting the scanning mirror and focusing mirror, the laser beam acts on the silver layer on the electrode surface of the MCR so that the silver layer is gasified and the mass of the MCR is changed, changing the resonant frequency of the MCR. 


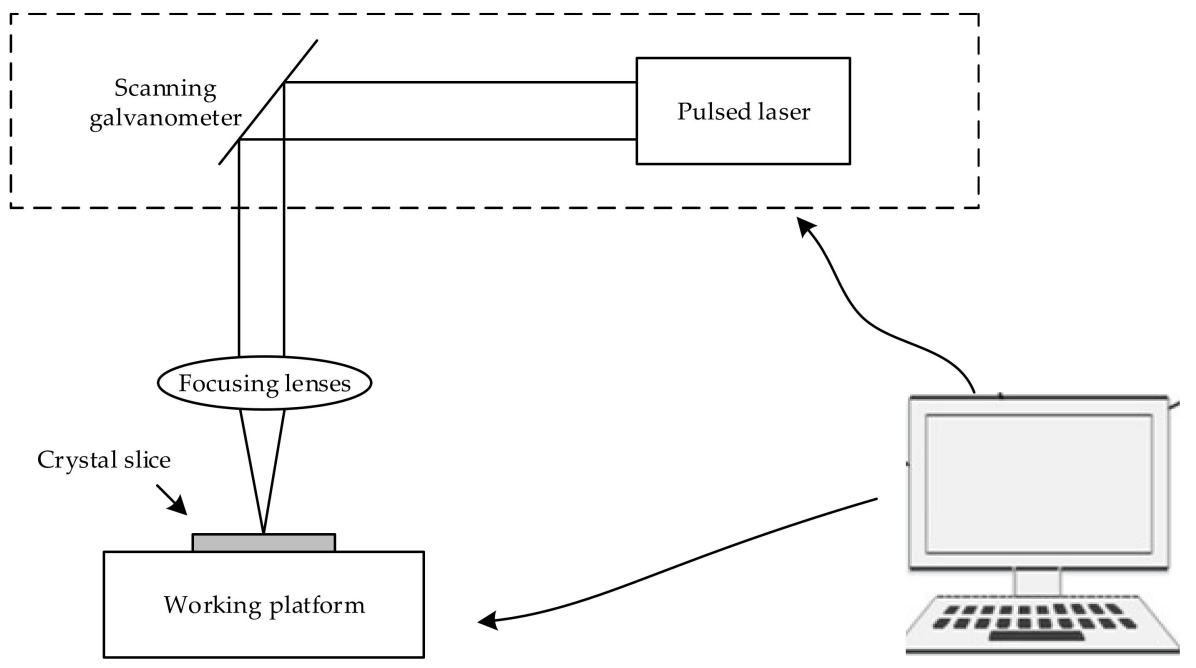

Figure 1. Schematic diagram of laser processing for frequency modulation.

The layout of the laser processing system for MCR frequency modulation is depicted in Figure 2. The carrier platform transports the MCR wafer from the feeding and discharging position to the processing position. The frequency detection of the MCR is carried out by the frequency detection probe. According to the frequency detection results, the laser output is controlled and the frequency of the MCR is continuously adjusted. After the frequency modulation of the current row of the MCR is completed, the laser processing system automatically enters the next row of frequency modulation operation until the MCR frequency modulation of the whole wafer is completed, and the carrier platform returns to the reclaiming and discharging position.

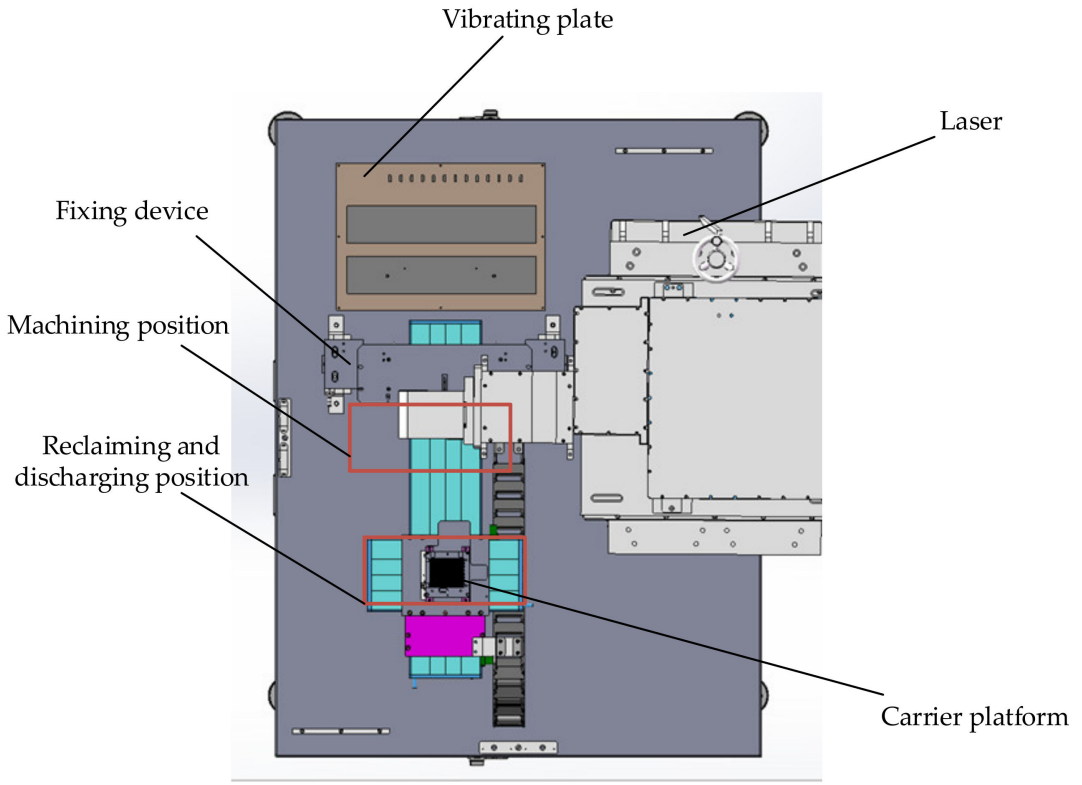

Figure 2. Layout of laser processing system for MCR frequency modulation.

YanXiang IPC-620H is selected as the industrial computer of the motion control system. YanHua PCI-1245E series motion control card is selected as the motion control card of the motion control system, which uses DSP and FPGA as the control unit and can communicate with the industrial computer through PCI bus. X-shaft and Y-shaft linear modules use Jacobs dgl-200. The Z-shaft uses a stepper motor and ball screw, and its model is LEY25RC50MG-SAN1. GaoChuang servo driver CDHD-4D5 is selected for a linear motor. The 
control driver of Z-shaft lift motor is IAI servo driver DS-S-C1. The GLPN-M fiber laser of IPG laser company is used as the laser processing device. The power, frequency and scanning galvanometer of the laser are controlled by LMCFIBER control card. The linewidth of the laser is within $20 \mu \mathrm{m}$. The pulse width is $1.5 \mathrm{~ns}$. The laser wavelength is $532 \mathrm{~nm}$. The pulse energy is $16 \mu \mathrm{J}$. The beam quality is less $1.2 \mathrm{M}^{2}$. The maximum output power of the laser is $15 \mathrm{~W}$. The pulse frequency of the laser is adjustable from $100 \mathrm{KHz}$ to $1200 \mathrm{KHz}$.

\subsection{Performance Requirements of Laser Processing Control System for MCR Frequency Modulation}

Combined with the actual production needs of the laser processing system for frequency modulation, in the laser processing for MCR frequency modulation, the performance requirements are as follows.

(1) Reliability: Reliability mainly refers to the frequency of equipment failure during long-term operation. Taking the average number of failures per week as the reliability evaluation index, the number of failures per week is required to be less than 1 .

(2) Over-frequency Rate: Over-frequency refers to the frequency exceeding the adjustable range in the process of MCR frequency modulation. According to the engineering requirements, it should be ensured that after the processing of $64 \mathrm{MCRs}$ in each row is completed, the number of over-frequency products is less than or equal to 1 , that is, the over-frequency rate is less than or equal to $1.56 \%$.

(3) Efficiency: Production efficiency refers to the number of MCRs modulated by the system per unit time. In order to meet the daily production needs, the equipment needs to complete the frequency modulation of each row of MCRs within $320 \mathrm{~s}$.

According to the above analysis, the performance requirements of laser processing control systems for MCR frequency modulation are listed in Table 1. In order to meet the requirements of over-frequency rate and efficiency, it is necessary to select appropriate control parameters such as power, frequency and machining speed.

Table 1. Performance requirements and indexes of laser processing control system for MCR frequency modulation.

\begin{tabular}{ccc}
\hline Performance Requirements & Evaluating Indicator & Index Value \\
\hline Reliability & Fault alarm rate, $\tau$ (Times $/$ Week) & $\tau<1$ \\
Over-frequency rate & Over-frequency rate of laser processing for & $\mu<1.56 \%$ \\
Efficiency & Frequency modulation, $\mu$ \\
frency modulion time of single row of & MCRs, $t(\mathrm{~s})$ & $\mathrm{t}<320 \mathrm{~s}$ \\
\hline
\end{tabular}

\section{Laser Processing Control Method for MCR Frequency Modulation}

\subsection{Workflow of Laser Processing Control System for MCR Frequency Modulation}

The automatic operation process of the laser processing control system for MCR frequency modulation is depicted in Figure 3. It mainly includes the following steps: (1) Parameters are set. (2) The carrier platform moves to the feeding and discharging position. The wafer of the MCRs is sucked tightly by a vacuum pump under the carrier platform after positioning is completed. (3) The left and right top pins return to the starting positions, and the carrier platform is transported to the machining position by the carrying device. (4) Each MCR is in contact with the frequency detection probe for frequency detection. (5) The laser performs frequency modulation on the MCRs. (6) After the frequency modulation of the current MCR is completed, the carrier platform automatically transports the wafer to the next row for processing until all 16 rows of the MCR are processed. (7) After the frequency modulation of all the MCRs are completed, the carrier platform descends, the vacuum pump of the suction cup is closed and the moving device moves the carrier platform to the reclaiming and discharging position. 

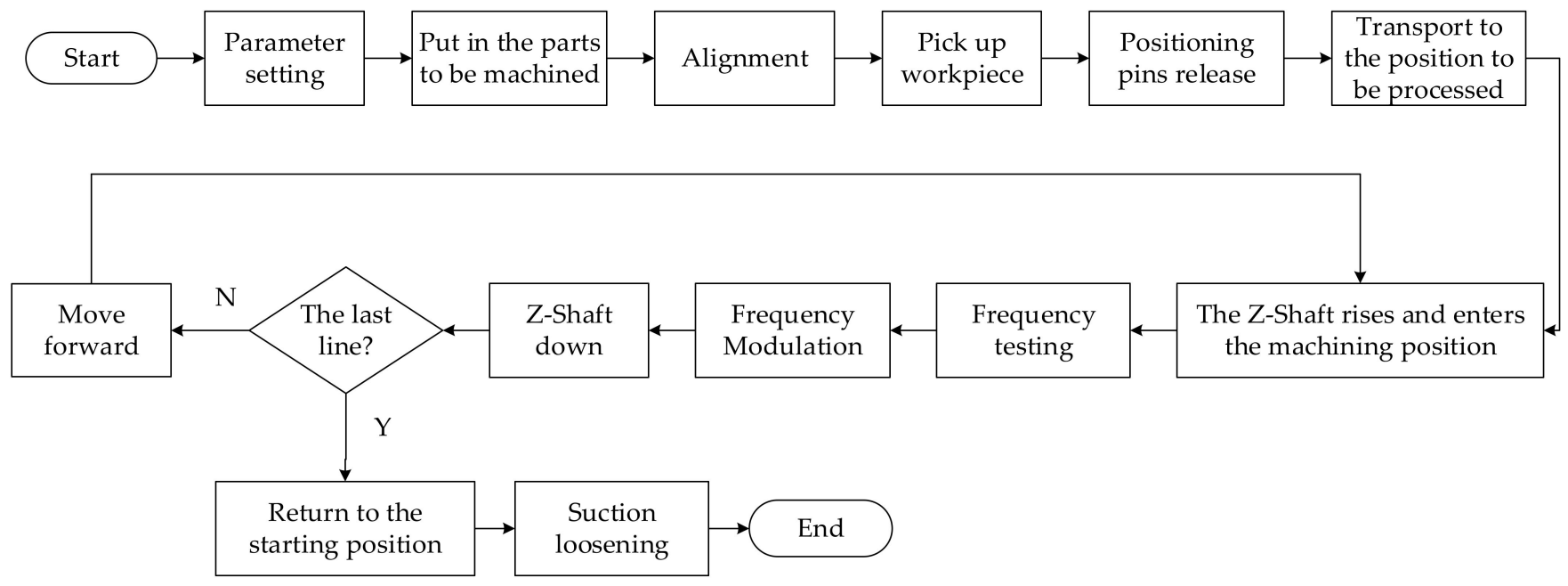

Figure 3. Automatic operation flow chart of laser process for MCR frequency modulation.

In the automatic operation of laser processing for MCR frequency modulation, each row of MCRs needs laser frequency modulation multiple times to achieve the target frequency value. The frequency modulation completion time of each MCR may be different. Therefore, in the frequency modulation process of each row of MCRs, the frequency modulation detailed process is depicted in Figure 4. According to the detected frequency and the set range of processing, the MCRs are divided into rejects, workable products and qualified products. The reject is the MCR of which the frequency cannot be adjusted to reach the target frequency range. The workable product is the MCR of which the frequency can be adjusted to reach the target frequency range. The qualified product is the MCR of which the frequency is within the target frequency range. The reject will be marked as the defective product, and frequency modulation operation will not be performed. According to the difference between the detected current frequency and the target frequency, workable MCRs will be laser-processed to modulate their frequencies.

After each round of laser frequency modulation, frequency detection will be carried out again. According to the detected frequency, the workable MCR will be processed again until the maximum number of processing times is reached. After reaching the maximum number of processing times, the last frequency detection will be carried out and the unqualified products will be marked as rejects.

\subsection{Motion Control Method of Laser Processing Carrier Platform for MCR Frequency Modulation}

3.2.1. Linear Motor Mathematical Model of Laser Processing Carrier Platform for MCR Frequency Modulation

In the laser processing control system for MCR frequency modulation, the positions of laser and frequency monitoring probe are fixed, so only when the MCR wafer moves to the target position can the laser processing for frequency modulation be carried out. In order to ensure motion accuracy, the platform is driven by the linear motor. In order to simplify the analysis of the linear motor, it is assumed that the permanent magnets in the linear motor are uniformly distributed, and the effects of eddy current and magnetic circuit saturation hysteresis loss are ignored. The $\mathrm{d}-\mathrm{q}$ axis mathematical model is used to analyze motor performance, and the voltage equation of the permanent magnet synchronous linear motor is established [21].

$$
\left\{\begin{array}{l}
\mathrm{u}_{\mathrm{q}}=\mathrm{Ri}_{\mathrm{q}}+\psi_{\mathrm{q}}+\omega_{\mathrm{r}} \psi_{\mathrm{d}} \\
\mathrm{u}_{\mathrm{d}}=\mathrm{Ri}_{\mathrm{d}}+\psi_{\mathrm{d}}+\omega_{\mathrm{r}} \psi_{\mathrm{q}}
\end{array}\right.
$$




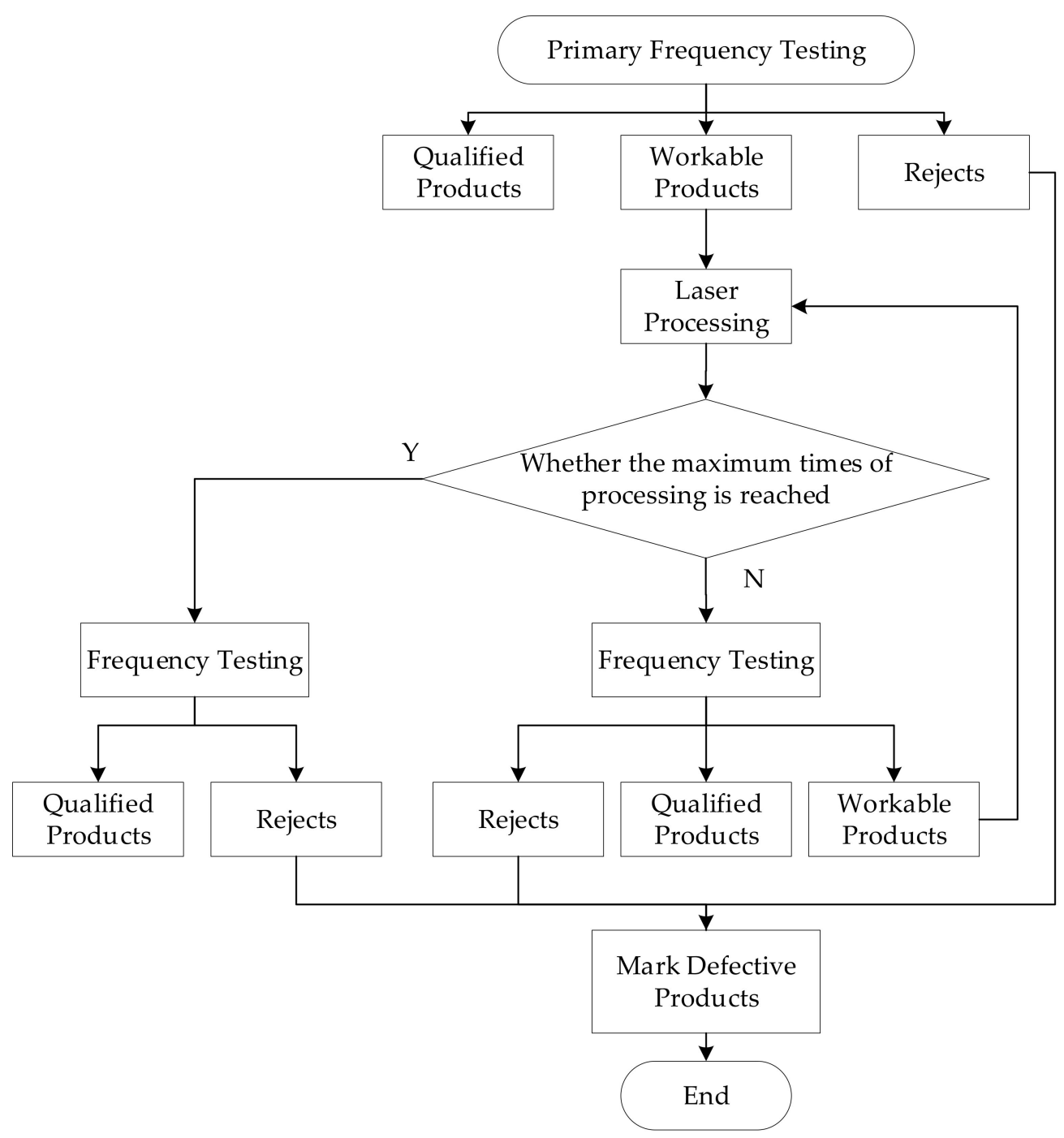

Figure 4. Frequency modulation flow chart.

The flux linkage equation of linear motor is as follows.

$$
\left\{\begin{array}{l}
\psi_{\mathrm{q}}=\mathrm{L}_{\mathrm{q}} \mathrm{i}_{\mathrm{q}} \\
\psi_{\mathrm{d}}=\mathrm{L}_{\mathrm{d}} \mathrm{i}_{\mathrm{d}}+\psi_{\mathrm{f}}
\end{array}\right.
$$

where $u_{d}$ and $u_{q}$ are the voltage components on the $\mathrm{d}-\mathrm{q}$ axis, $V ; i_{d}$ and $i_{q}$ are the current components on the $\mathrm{d}-\mathrm{q}$ axis, $A ; L_{d}$ and $L_{q}$ are the inductance components on the $\mathrm{d}-\mathrm{q}$ axis, $m H ; \psi_{d}$ and $\psi_{q}$ are the flux linkage vectors on the $\mathrm{d}-\mathrm{q}$ axis, $W b ; \psi_{f}$ is the coupling flux linkage of the stator permanent magnet in the winding, $W b ; R$ is the stator winding resistance, $\Omega$, and $\omega_{r}$ is the rotor angular speed, $\mathrm{rad} / \mathrm{s}$.

The electromagnetic thrust formula is as follows [21].

$$
\mathrm{F}_{\mathrm{e}}=\frac{3 \pi}{2 \tau_{\mathrm{n}}}\left[\psi_{\mathrm{f}} \mathrm{i}_{\mathrm{q}}+\left(\mathrm{L}_{\mathrm{d}}-\mathrm{L}_{\mathrm{q}}\right) \mathrm{i}_{\mathrm{d}} \mathrm{i}_{\mathrm{q}}\right]
$$

The electromagnetic thrust of the linear motor is controlled by the q-axis current component, that is, when the excitation component current is 0 , the electromagnetic thrust can be expressed as the following formula.

$$
\mathrm{F}_{\mathrm{e}}=\frac{3 \pi}{2 \tau_{\mathrm{n}}} \psi_{\mathrm{f}} \mathrm{i}_{\mathrm{q}}=\mathrm{K}_{\mathrm{m}} \mathrm{i}_{\mathrm{q}}
$$


The mechanical motion equation of linear motor is the following formula.

$$
\mathrm{F}_{\mathrm{e}}=\mathrm{K}_{\mathrm{m}} \mathrm{i}_{\mathrm{q}}=\mathrm{Mv}^{\prime}+\mathrm{Bv}+\mathrm{F}
$$

where $M$ is the motor mover mass, $\mathrm{kg} ; B$ is motor viscous friction coefficient, $N \cdot s / m$; $F$ is the disturbance of thrust fluctuation caused by load resistance, friction and end effect, $N$; $K_{m}$ is the motor force constant, $N / A ; v$ is the operating velocity, $\mathrm{m} / \mathrm{s}$, and $\tau$ is the polar distance, $m m$.

The voltage balance equation is as follows.

$$
\mathrm{L} \frac{\mathrm{di}_{\mathrm{q}}}{\mathrm{dt}}+\mathrm{Ri}_{\mathrm{q}}=\mathrm{u}_{\mathrm{q}}-\varphi_{\mathrm{f}} \mathrm{Pv}=\mathrm{u}_{\mathrm{q}}-\mathrm{K}_{\mathrm{e}} \mathrm{v}
$$

where $P$ is the pole-pair number and $K_{e}=\phi_{f} P$ is the back EMF coefficient, $V /(\mathrm{m} / \mathrm{s})$.

Ignoring the effect of load disturbance during simulation, the linear motor model can be simplified, and the simulation model is depicted in Figure 5, where $\mathrm{s}$ is the Laplace operator.

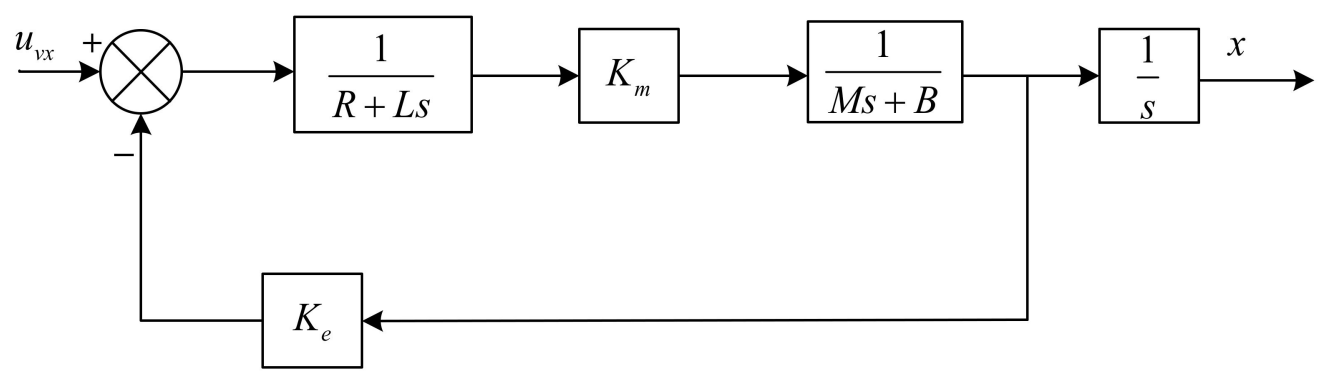

Figure 5. Simulation model of linear motor.

Since the main travel direction of the platform is the $\mathrm{X}$ direction, the linear motor used in the $\mathrm{X}$ direction is designed and analyzed, and the motor parameters are listed in Table 2.

Table 2. Parameter table of $\mathrm{X}$-shaft linear motor.

\begin{tabular}{cc}
\hline Name & Parameter \\
\hline Motor mover mass & $M=21.3 \mathrm{~kg}$ \\
Motor force constant & $K_{m}=72.8 \mathrm{~kg}$ \\
Back EMF coefficient of motor & $K_{e}=36 \mathrm{~V} /(\mathrm{m} / \mathrm{s})$ \\
Motor viscous friction coefficient & $B=0.01 \mathrm{~N} \cdot \mathrm{s} / \mathrm{m}$ \\
Motor inductance & $L=24 \mathrm{mH}$ \\
Stator winding resistance & $R=3 \Omega$ \\
Motor polar distance & $\tau=36 \mathrm{~mm}$ \\
\hline
\end{tabular}

\subsubsection{Carrier Platform Control Method of Laser Processing for MCR Frequency}

Modulation Based on Fuzzy PID

Since the linear motor current controller and speed controller are set in the driver, the three closed-loop control mode based on position control mode is selected to control the linear motor. In order to facilitate the analysis, the current loop is regarded as a linear gain, $\mathrm{K}_{\mathrm{c}}$, and the velocity loop controller is a Proportion-Integral (PI) controller with certain parameters. The velocity loop PI controller transfer function of the linear motor is shown in formula 8 [21].

$$
\mathrm{G}_{\mathrm{v}}(\mathrm{s})=\mathrm{K}_{\mathrm{v}}\left(1+\frac{1}{\mathrm{~T}_{\mathrm{v}} \cdot \mathrm{s}}\right)=\frac{\mathrm{K}_{\mathrm{v}}\left(1+\mathrm{T}_{\mathrm{v}} \cdot \mathrm{s}\right)}{\mathrm{T}_{\mathrm{v}} \cdot \mathrm{s}}
$$

where $T_{V}$ is the integral time constant of the velocity loop and $\mathrm{K}_{\mathrm{V}}$ is the proportional gain of the velocity loop. 
The position loop PID control transfer function of the linear motor servo system is as follows.

$$
\mathrm{G}_{\mathrm{p}}(\mathrm{s})=\mathrm{K}_{\mathrm{p}}\left(1+\frac{1}{\mathrm{~T}_{\mathrm{i}} \cdot \mathrm{s}}+\mathrm{T}_{\mathrm{d}} \cdot \mathrm{s}\right)=\mathrm{K}_{\mathrm{p}}+\frac{\mathrm{K}_{\mathrm{i}}}{\mathrm{s}}+\mathrm{K}_{\mathrm{d}} \cdot \mathrm{s}
$$

where $\mathrm{K}_{\mathrm{p}}$ is the proportional coefficient of the position loop, $\mathrm{K}_{\mathrm{i}}$ is the integral coefficient of the position loop and $K_{d}$ is the differential time constant of the position loop.

The servo control model of the linear motor based on the PID control method is depicted in Figure 6.

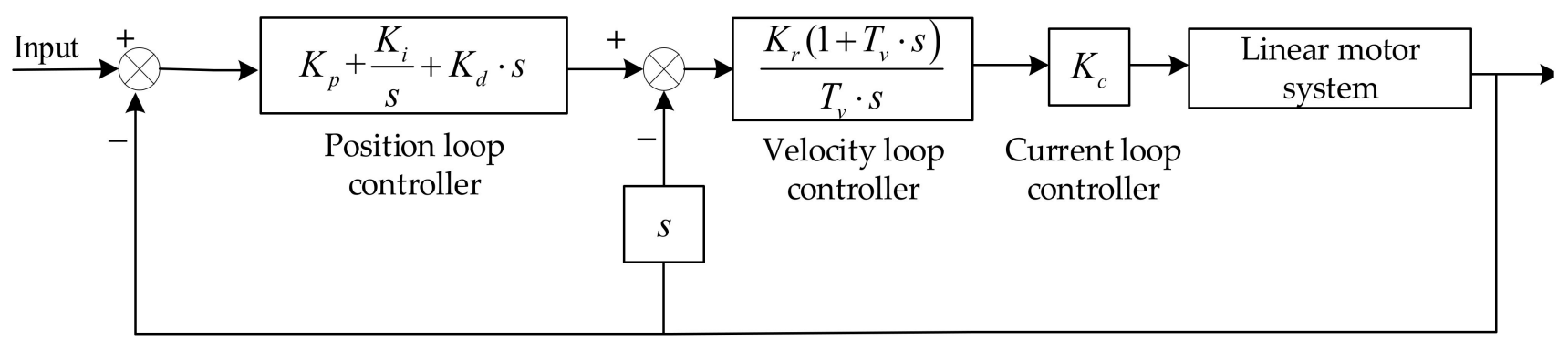

Figure 6. Servo control model of linear motor based on PID control method.

The proportional, integral and differential coefficients of the position loop controller are adjusted according to the PID parameter tuning principle. The initial control coefficients of the adjusted position loop are $K_{p}=31.24, K_{i}=3.45$ and $K_{d}=15.78$.

In the current industrial application, the fuzzy PID control method has never been applied to the MCR frequency modulation carrier related equipment. Because of the short moving distance and high precision of the MCR frequency modulation carrier platform, the control method based on fuzzy PID can respond in time, which is more suitable for the production requirements of MCR laser frequency modulation equipment to solve the lag effect of traditional PID control [22]. Take the motion error and the motion error change rate of the platform as the error input and the two-dimensional fuzzy controller of fuzzy PID control as the controller of the platform. The controller structure is shown in Figure 7. The error input in the fuzzy controller is the trajectory error of the actual motion point of the MCR carrier platform, and the error differential input is the variation of the trajectory error.

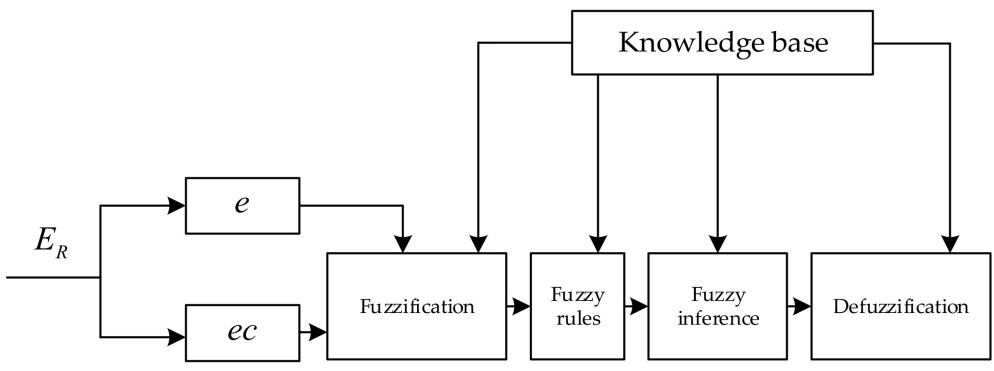

Figure 7. Fuzzy controller structure.

The fuzzy subsets of input and output variables are set to seven types, namely: NB (negative big), NM (negative middle), NS (negative small), NO (zero), PS (positive small), PM (positive middle) and PB (positive big). The motion trajectory error and the motion trajectory error variation of the actual motion point of the MCR carrier platform, e and ec, respectively, are taken as input. $\Delta \mathrm{K}_{\mathrm{p}}, \Delta \mathrm{K}_{\mathrm{i}}$ and $\Delta \mathrm{K}_{\mathrm{d}}$ are taken as output. The domain range is determined as $[-6,6]$. The 'Mamdani' reasoning method and the triangular membership function are used as the fuzzy controller to deal with the fuzzy subset transformed from the input and output variables.

In the movement of the carrier platform, there is a certain deviation between the actual trajectory point and the expected trajectory point. The absolute value of the dif- 
ference between the actual trajectory points and the expected trajectory point is used as the error input to directly obtain the position difference between the current position and the expected position of the MCR carrier platform. The error variation is calculated with the difference between the absolute values of the error values of the trajectory in the two moments. Through the error variation, it can be judged whether the difference between the actual trajectory and the expected trajectory will continue to increase or decrease the next time. The proportional coefficient fuzzy control rule table is designed and is as listed in Table 3. The integral coefficient fuzzy control rule table is listed in Table 4. The differential coefficient fuzzy control rule table is listed in Table 5.

Table 3. $\Delta K_{p}$ Fuzzy control rule table.

\begin{tabular}{cccccccc}
\hline NB & NM & NS & ZO & PS & PM & PB \\
\hline NB & PB & PM & PM & PS & PS & ZO & NS \\
NM & PM & PM & PS & PS & ZO & ZO & NS \\
NS & PM & PS & PS & ZO & ZO & NS & NS \\
ZO & PS & PS & ZO & ZO & NS & NS & NM \\
PS & PS & ZO & ZO & NS & NS & NM & NM \\
PM & ZO & ZO & NS & NS & NM & NB & NB \\
PB & ZO & NS & NS & NS & NM & NB & NB \\
\hline
\end{tabular}

Table 4. $\Delta K_{i}$ Fuzzy control rule table.

\begin{tabular}{ccccccccc}
\hline NB & NB & NM & NS & ZO & PS & PM & PB \\
\hline NB & & & & & & & \\
NM & NB & NM & NM & NA & NS & ZO & ZO \\
NS & NM & NS & NS & NA & ZO & ZO & PS \\
ZO & NS & NS & ZO & ZO & PO & PS & PM \\
PS & NS & ZO & ZO & PS & PS & PM & PB \\
PM & ZO & ZO & PS & PS & PM & PM & PB \\
PB & ZO & PS & PS & PM & PM & PB & PB \\
\hline
\end{tabular}

Table 5. $\Delta K_{d}$ Fuzzy control rule table.

\begin{tabular}{ccccccccc}
\hline NB & NB & NS & ZO & PS & PM & PB \\
\hline NB & PM & NM & NB & NB & NB & NM & PS \\
NS & PS & NS & NM & NB & NM & NM & PS \\
ZO & PS & NS & NS & NM & NM & NS & ZO \\
PS & ZO & NS & NS & NS & ZO & ZO & ZO \\
PM & ZO & ZO & NS & NS & ZO & ZO & ZO \\
PB & PM & NS & ZO & PS & PS & PS & PB \\
& PB & ZO & PS & PS & PM & PM & PB \\
\hline
\end{tabular}

Combining the fuzzy controller with the designed PID position controller, the control model of the fuzzy PID position controller for linear motor can be obtained, which is depicted in Figure 8. 


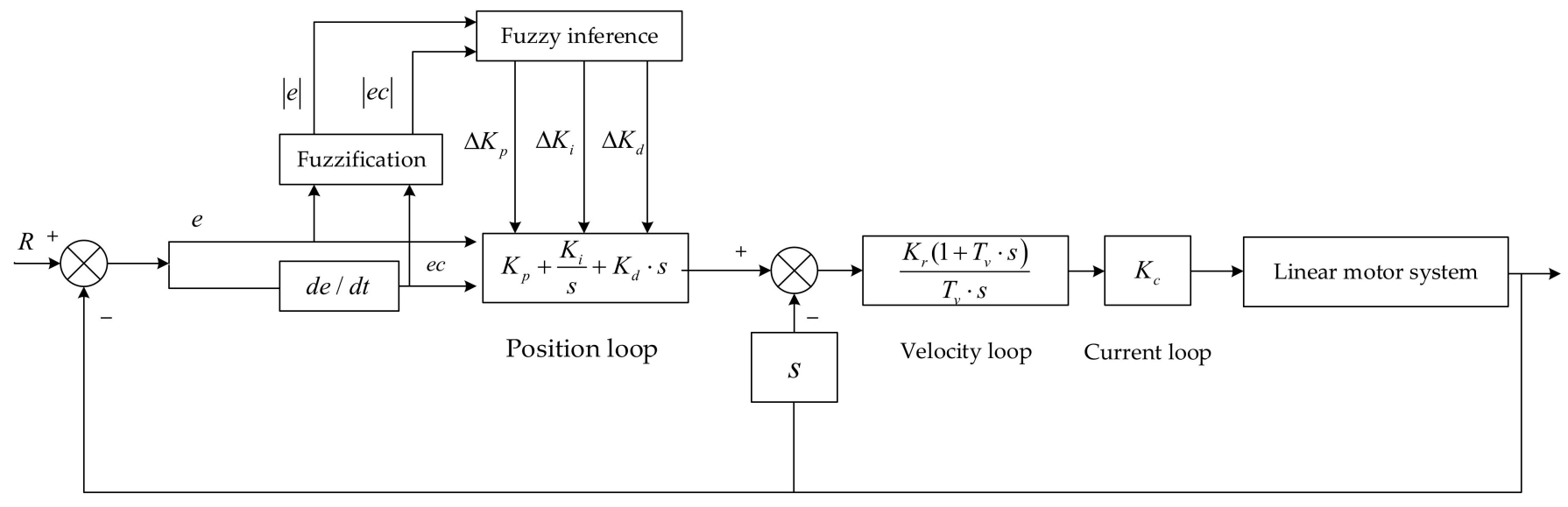

Figure 8. Control model of fuzzy PID position controller for linear motor.

\section{Design of Laser Processing Control System for MCR Frequency Modulation}

4.1. Hardware and Software of Laser Processing Control System for MCR Frequency Modulation

In order to complete the laser processing for MCR frequency modulation, it is necessary to integrate the motion control module, frequency detection module, laser processing module, man-machine interface and so on. The control system function modules are depicted in Figure 9.

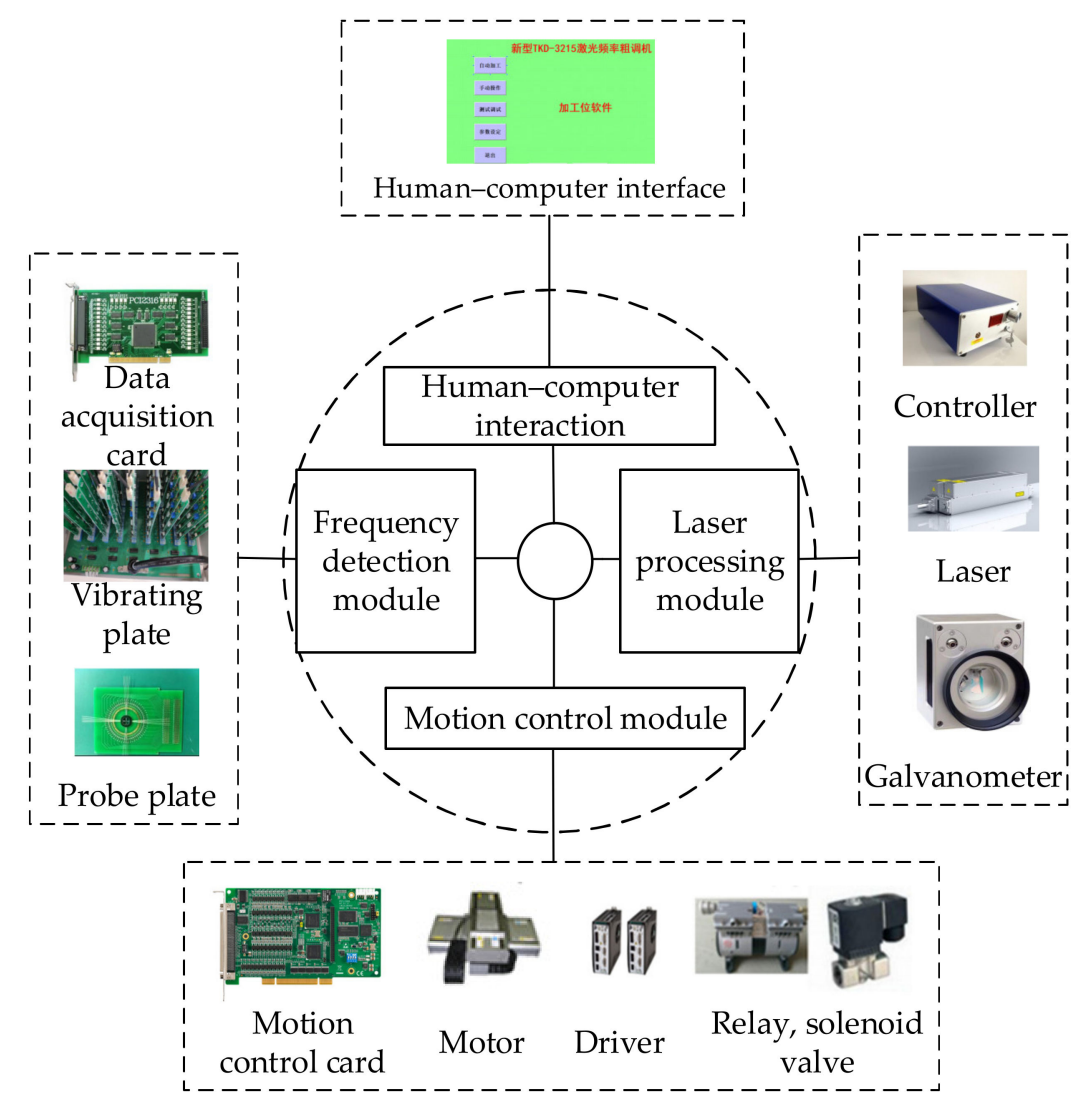

Figure 9. Structure diagram of laser processing control system for MCR frequency modulation.

The motion control scheme based on the motion control card is adopted in the system, and the multi-shaft coordinated control of multiple servo motors is realized by combining the motion control card with an industrial computer. The control program is designed and implemented by multiple industrial control software in the Windows system. The data 
transmission is depicted in Figure 10. Both the data acquisition card PCI-8821 and the motion control card PCI-1245E communicate with the host computer through the PCI bus.

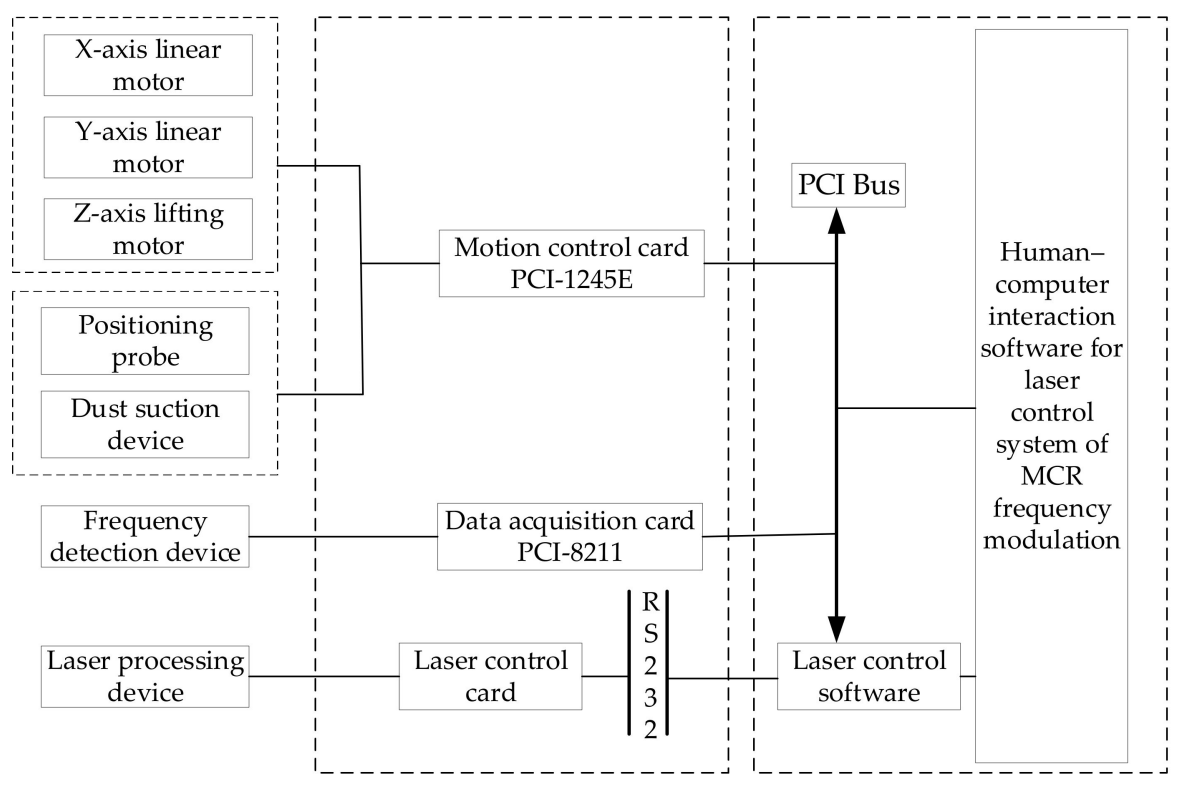

Figure 10. Data transmission link diagram.

The pneumatic circuit of positioning mechanism and suction mechanism are depicted in Figure 11. The power of each cylinder is provided by compressed air, and the total circuit pressure is adjusted to $0.5 \mathrm{MPa}$. When the wafer of the MCRs is transported to the carrier platform, the solenoid valve is activated. The positioning cylinder drives the positioning pin to align the wafer of the MCRs, of which the velocity can be adjusted by changing the opening of the throttle valve. Therefore, the motion velocity of the positioning pin is adjusted, and the wafer damage caused by excessive thrust can be avoided. After the alignment is completed, the alignment pin returns, the suction cylinder is activated and the MCR wafer is fixed.

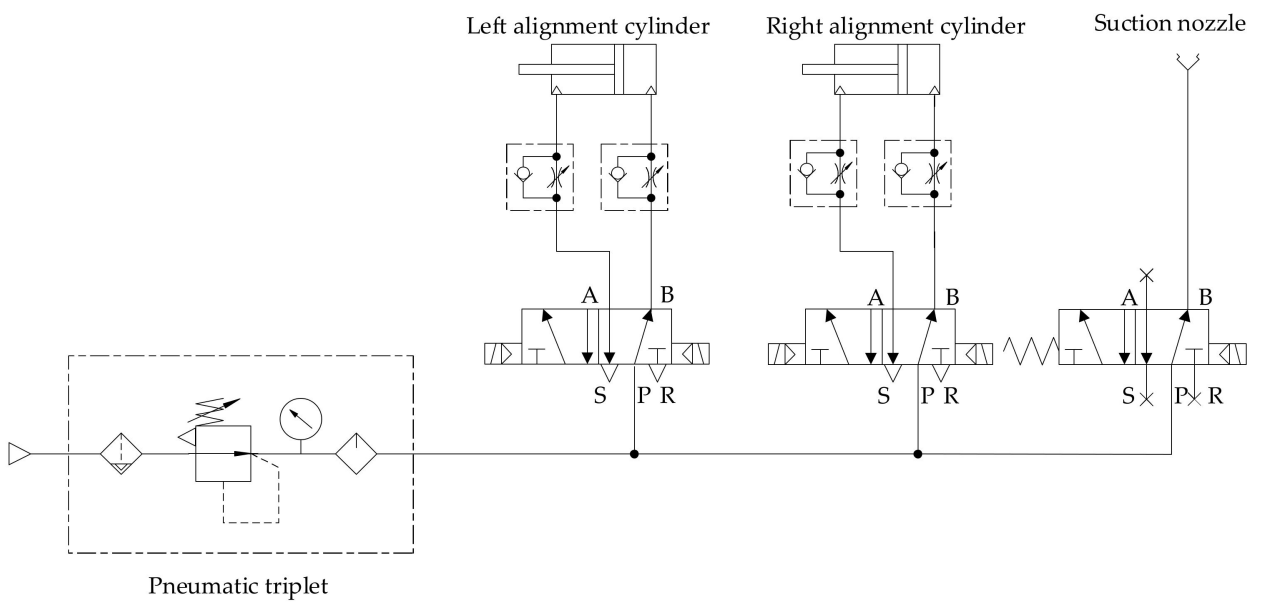

Figure 11. Pneumatic circuit diagram.

The man-machine interface of the control system consists of the main interface, the parameter setting interface, the manual operation interface and the automatic machining interface. The parameter setting interface is responsible for setting the processing parameters, which mainly include the processing target frequency range, the laser processing parameters, the number of laser processing times and the set position. The manual operation interface is mainly responsible for the tuning of each motion shaft, laser and frequency test 
system. Before automatic processing, the position parameters of each shaft and laser are determined by manual tuning and the frequency test system is tested and confirmed. The automatic processing interface can realize the automatic operation control of the system.

\subsection{Prototype and Function Verification of Laser Processing Control System for MCR Frequency Modulation}

In order to ensure the positioning accuracy of the movement of the carrier platform and verify the correctness of the motion control module, after the wafer is fixed on the carrier platform, the actual motion position of the carrier platform is tracked and displayed. The detection results are shown in Table 6. The digital signal resolution of the ATOM grating used in the linear motor can reach $1 \mathrm{~nm}$ after subdivision. The carrier platform is controlled to realize single-stroke $100 \mathrm{~mm}$ linear motion in the $\mathrm{X}$ and $\mathrm{Y}$ directions. The positioning error of the $X$-shaft is between $0.8 \mu \mathrm{m}$ and $1.7 \mu \mathrm{m}$, and the positioning error of the Y-shaft is between $0.7 \mu \mathrm{m}$ and $1.6 \mu \mathrm{m}$, both below $10 \mu \mathrm{m}$, reaching the positioning accuracy required by the carrier platform.

Table 6. Actual displacement distance of each shaft.

\begin{tabular}{cccc}
\hline X-Shaft Actual Displacement(mm) & \multicolumn{2}{c}{ Y-Shaft Actual Displacement(mm) } \\
\hline (a) & (b) & (a) & (b) \\
100.0012 & 100.0007 & 100.0007 & 99.9984 \\
100.0008 & 100.0013 & 99.9986 & 100.0012 \\
100.0017 & 99.9985 & 100.0009 & 100.0010 \\
100.0017 & 100.0011 & 99.9985 & 100.0028 \\
99.9991 & 100.0012 & 100.0009 & \\
\hline
\end{tabular}

In order to verify the motion control accuracy of the carrier platform and ensure that the error between the actual position and the target position of the MCR is within the target range, whether the MCR is transported to the appropriate position can be determined by observing the contact point position of the frequency detection probe and the MCR. The photograph of the contact point is shown in Figure 12.

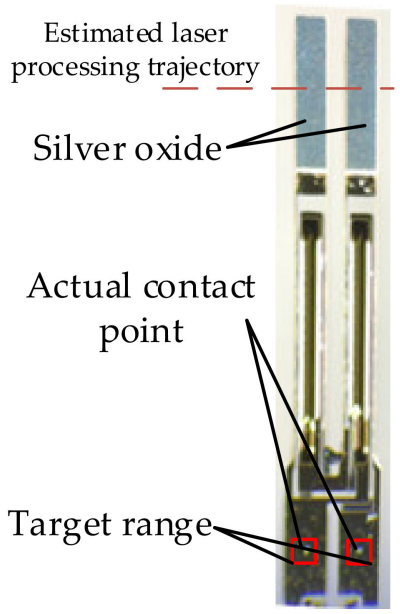

(a)

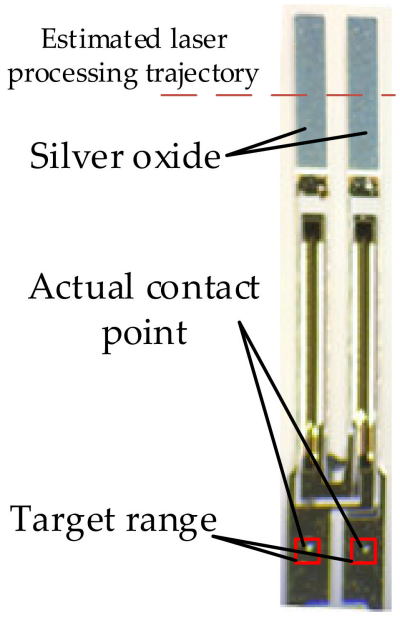

(b)

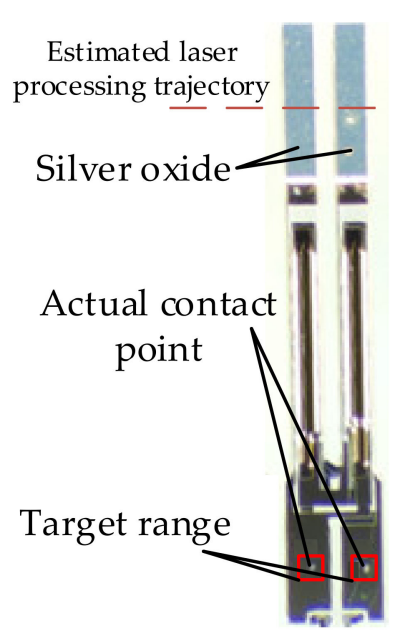

(c)

Figure 12. Verification of actual contact point position: (a) Row 1; (b) Row 8; (c) Row 16.

In order to verify the laser output function, in the manual tuning interface of the host computer software, the laser photo paper is used to test the functions of laser spotlight output, short-line segment scanning and top scanning to detect whether the laser can output specified light patterns to meet the specified requirements. The length of short-line segment scanning is compared with the set length in the parameters, and then the parameters are 
adjusted accordingly if the length cannot meet the set value. At the same time, the laser power is measured by a power meter and compared with the set power to ensure that the laser output power is appropriate. Finally, the electrode part of the MCR is processed by laser and whether the frequency of the MCR changed is verified.

After each function verification is completed, the automatic operation function verification is carried out. At the automatic processing interface, the functions of automatic measurement of all MCRs, automatic processing of a piece and processing of a specified row are tested to ensure that the automatic operation functions can be realized normally. The data in the processing statistics interface are verified to be consistent with the results obtained by actual processing.

\section{Process Parameter Optimization of Laser Control System for MCR Frequency Modulation}

\subsection{Laser Characteristics Analysis of MCR Frequency Modulation}

In the laser processing of MCR frequency modulation, the laser power, laser frequency and laser processing speed play a decisive role in frequency modulation production. Experiments with different parameters are carried out. The results of MCR electrode surface processing are observed under a microscope and the results are depicted in Figure 13. The laser power, laser frequency and laser processing speeds of group A are $5 \mathrm{~W}, 200 \mathrm{KHz}$ and $800 \mathrm{~mm} / \mathrm{s}$, the parameters of group B are $8 \mathrm{~W}, 400 \mathrm{KHz}$ and $400 \mathrm{~mm} / \mathrm{s}$, and the parameters of group C are $10 \mathrm{~W}, 500 \mathrm{KHz}$ and $200 \mathrm{~mm} / \mathrm{s}$. When the selected laser power and frequency are too low and the laser processing speed is too fast, it is difficult to etch the silver layer of the electrode of the MCR, and the frequency modulation fails. The higher the laser power, the greater the heat flux acting on the surface of the electrode silver layer of the MCR per unit time, the more heat absorbed by the silver layer per unit area, the larger gasification and melting area of the silver layer and the greater the frequency change of the MCR. The higher the laser frequency, the more times the laser pulse acts on the silver layer per unit time and the faster gasification of the silver layer. If the processing speed is too fast, it is difficult for the electrode silver layer to absorb enough heat to gasify, and it is impossible to adjust the frequency of the MCR to the target frequency. When the selected laser power is too high, the laser frequency is too high, the laser processing speed is too slow and the etching depth and width of the electrode silver layer of the MCR will increase. However, when the processing is carried out with large laser power and laser frequency and slow laser processing speed, the melting area of the silver layer will also increase, and these areas will be oxidized and blackened after cooling, which affects the appearance of the MCR [23]. In order to ensure that the electrode silver layer of the MCR can be quickly etched without excessive black edges, according to the experimental data, it is determined that the laser power is between $6 \mathrm{~W}$ and $9 \mathrm{~W}$, the laser frequency is between $200 \mathrm{KHz}$ and $500 \mathrm{KHz}$ and the laser processing speed is between $200 \mathrm{~mm} / \mathrm{s}$ and $800 \mathrm{~mm} / \mathrm{s}$.

\subsection{Orthogonal Experiment and Result Analysis of Laser Processing Control Parameters for MCR Frequency Modulation}

Because laser power, laser frequency and laser processing speed have influence on the frequency modulation, the single-variable control method can only reflect the influence of each parameter on the results of MCR frequency modulation. In order to obtain appropriate laser processing control parameters and comprehensively consider the influence of various control parameters on frequency modulation results, orthogonal experiments are used for analysis. The three control parameters-laser power, laser frequency and laser processing speed-are selected as experimental factors, represented by A, B and C, of the orthogonal experiment. Based on the experimental results of laser control parameters, the range of laser power is from $6 \mathrm{~W}$ to $9 \mathrm{~W}$, the range of laser frequency is from $200 \mathrm{KHz}$ to $500 \mathrm{KHz}$ and the range of laser processing speed is from $200 \mathrm{~mm} / \mathrm{s}$ to $800 \mathrm{~mm} / \mathrm{s}$. Each factor has four levels, and the factor level table is listed in Table 7. 


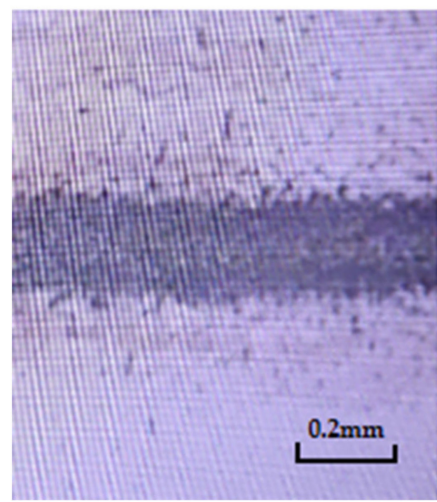

(a)

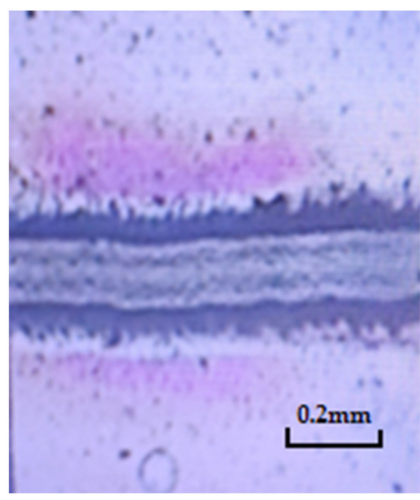

(b)

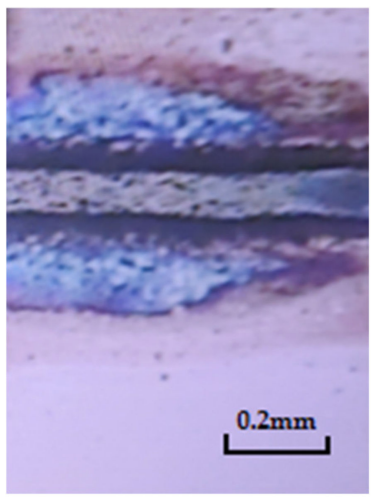

(c)

Figure 13. Experiment results of MCR frequency modulation with different parameters under the $50 \times$ electron microscope: (a) $5 \mathrm{~W}, 200 \mathrm{KHz}, 800 \mathrm{~mm} / \mathrm{s}$; (b) $8 \mathrm{~W}, 400 \mathrm{KHz}, 400 \mathrm{~mm} / \mathrm{s}$; (c) $10 \mathrm{~W}$, $500 \mathrm{KHz}, 200 \mathrm{~mm} / \mathrm{s}$.

Table 7. Factor level table.

\begin{tabular}{ccccc}
\hline $\begin{array}{c}\text { Level } \\
\text { Factor }\end{array}$ & $\mathbf{1}$ & $\mathbf{2}$ & $\mathbf{3}$ & $\mathbf{4}$ \\
\hline A: Laser power/W & 6 & 7 & 8 & 9 \\
B: Laser frequency/KHz & 200 & 300 & 400 & 500 \\
C: Laser processing speed $/ \mathrm{mm} / \mathrm{s}$ & 200 & 400 & 600 & 800 \\
\hline
\end{tabular}

According to the above analysis, the orthogonal experiment is designed as an experiment of three factors and four levels. The $\mathrm{L}_{16}\left(4^{5}\right)$ orthogonal table is selected for the orthogonal experiment, and the two extras are set as blank columns. Sixteen representative experimental combinations are selected from the experiment, and the orthogonal experiment design and experimental results are listed in Table 8.

Table 8. $\mathrm{L}_{16}\left(4^{5}\right)$ Orthogonal experiment and results.

\begin{tabular}{cccccc}
\hline \multirow{2}{*}{ Experiment Number } & \multicolumn{3}{c}{ Factor Level } & \multicolumn{3}{c}{ Evaluating Indicator } \\
\cline { 2 - 5 } & A & B & C & Over-Frequency Rate/\% & Processing Time/s \\
\hline 1 & 1 & 1 & 1 & 1.45 & 289.3 \\
2 & 1 & 2 & 2 & 1.27 & 300.8 \\
3 & 1 & 3 & 3 & 1.12 & 311.6 \\
4 & 1 & 4 & 4 & 0.98 & 323.7 \\
5 & 2 & 1 & 2 & 1.98 & 291.4 \\
6 & 2 & 2 & 1 & 1.88 & 271.2 \\
7 & 2 & 3 & 4 & 1.31 & 316.9 \\
8 & 2 & 4 & 3 & 1.51 & 293.7 \\
9 & 3 & 1 & 3 & 1.78 & 316.2 \\
10 & 3 & 2 & 4 & 2.56 & 267.7 \\
11 & 3 & 3 & 1 & 2.22 & 281.2 \\
13 & 3 & 4 & 2 & 1.85 & 306.2 \\
14 & 4 & 1 & 4 & 2.18 & 289.3 \\
16 & 4 & 2 & 3 & 2.42 & 273.1 \\
\end{tabular}

The range analysis method of the orthogonal experiment is used to analyze the influence degree of each laser control parameter on the evaluation index. The ranges of laser frequency and laser processing speed are calculated respectively. The range analysis table 
of laser over-frequency rate and the range analysis table of laser processing time of MCR frequency modulation are listed in Tables 9 and 10.

Table 9. Range analysis table of over-frequency rate of MCR frequency modulation.

\begin{tabular}{cccc}
\hline \multirow{2}{*}{ Essential Factor } & A (Laser Power) & B (Laser Frequency) & C (Processing Speed) \\
\cline { 2 - 4 } & Over-Frequency Rate/\% & Over-Frequency Rate/\% & Over-Frequency Rate/\% \\
\hline Ki1 & 4.74 & 7.33 & 9.01 \\
Ki2 & 6.68 & 7.41 & 8.21 \\
Ki3 & 8.82 & 7.56 & 6.74 \\
$\mathrm{Ki} 4$ & 9.3 & 7.6 & 5.94 \\
$\mathrm{Ki} 1$ & 1.185 & 1.8325 & 2.2525 \\
$\mathrm{Ki}$ 2 & 1.67 & 1.8525 & 2.0525 \\
$\overline{\mathrm{Ki}} 3$ & 2.08 & 1.89 & 1.685 \\
$\mathrm{Ki} 4$ & 2.325 & 1.9 & 1.485 \\
$\mathrm{Ri}$ & 1.14 & 0.0675 & 0.54 \\
Optimal level & $\mathrm{A} 1$ & $\mathrm{~B} 1$ & $\mathrm{C} 4$ \\
\hline Factor primary and & & $\mathrm{A}>\mathrm{C}>\mathrm{B}$ & \\
secondary sorting & &
\end{tabular}

Table 10. Range analysis table of processing time of MCR frequency modulation.

\begin{tabular}{cccc}
\hline \multirow{2}{*}{ Essential Factor } & A (Laser Power) & B (Laser Frequency) & C (Processing Speed) \\
\cline { 2 - 4 } & Processing Time/s & Processing Time/s & Processing Time/s \\
\hline Ki1 & 1225.4 & 1180.3 & 1087.3 \\
Ki2 & 1183.2 & 1177.5 & 1146.5 \\
Ki3 & 1158.5 & 1169.3 & 1198 \\
Ki4 & 1127.7 & 1167.7 & 1263 \\
Ki1 & 306.35 & 295.075 & 271.825 \\
Ki2 & 295.8 & 294.375 & 286.625 \\
Ki3 & 289.625 & 292.325 & 299.5 \\
Ki4 & 281.925 & 291.925 & 315.75 \\
Ri & 24.425 & 3.15 & 43.925 \\
Optimal level & A & B 1 & \\
\hline Factor primary and & & $\mathrm{C}>$ A $>$ B & \\
secondary sorting & & & \\
\hline
\end{tabular}

The optimal levels of laser power, laser frequency and laser processing speed on laser over-frequency rate are A1, B1 and C4, and the optimal levels for laser processing time are $\mathrm{A} 4, \mathrm{~B} 4$ and $\mathrm{C} 1$. In the actual production process, to ensure that the frequency modulation completion time of each row of MCRs meets the requirements, the over-frequency rate is reduced as much as possible to cut costs. Table 1 shows that the performance index of the laser control system is that the over-frequency rate is less than $1.56 \%$ and the processing time is less than $320 \mathrm{~s}$. After meeting the requirements of over-frequency rate, the shorter processing time is, the better the efficiency is. Comparing the data in Tables 9 and 10, only level 1 in factor A meets the requirement of over-frequency rate, and the levels in factor B and factor $\mathrm{C}$ all meet the requirement of over-frequency rate. Therefore, the results with the shortest processing time in qualified levels of A, B and C are selected as the optimal levels. In summary, the optimal levels of laser power, laser frequency and laser processing speed are: A1, B4 and C1.

The variance of the influence degree of each factor is calculated by statistical analysis software, and the variance analysis results of over-frequency rate and processing time are obtained and listed in Tables 11 and 12. In the variance results of the over-frequency rate of the MCR frequency modulation, the order of $\mathrm{F}$ ratios is $\mathrm{FA}>\mathrm{FC}>\mathrm{FB}$, that is, the influence of laser power on the over-frequency rate is the most obvious, followed by that of the laser 
processing speed, and the influence of laser frequency is the smallest. In the variance results of the processing time of MCR frequency modulation, the order of $\mathrm{F}$ ratios is FC > FA > $\mathrm{FB}$, that is, the influence of laser processing speed on processing time is the most obvious, followed by that of laser power, and the influence of laser frequency is the least. When $\alpha=0.05$, according to the $F$ distribution table, Since $F_{\alpha}(3,6)=4.76$. Since $F_{B}<F_{0.05}(3,6)$, it can be determined that laser frequency has no significant effect on the MCR frequency modulation.

Table 11. Variance analysis of over-frequency rate.

\begin{tabular}{ccccc}
\hline Variance Source & Sum of Squares of Deviations & Freedom & Variance & F \\
\hline A (Laser power) & 2.993 & 3 & 0.998 & 44.375 \\
B (Laser frequency) & 0.053 & 3 & 0.018 & 0.784 \\
C (Processing speed) & 1.174 & 3 & 0.391 & 17.409 \\
Experimental error & 0.135 & 6 & 0.022 & $/$ \\
Comprehensive & 4.446 & 16 & $/$ & $/$ \\
\hline
\end{tabular}

Table 12. Variance analysis of processing time.

\begin{tabular}{ccccc}
\hline Variance Source & Sum of Squares of Deviations & Freedom & Variance & F \\
\hline A (Laser power) & 1277.545 & 3 & 425.848 & 33.558 \\
B (Laser frequency) & 28.34 & 3 & 9.447 & 0.744 \\
C (Processing speed) & 4192.445 & 3 & 1397.482 & 110.125 \\
Experimental error & 76.14 & 6 & 12.69 & $/$ \\
Comprehensive & $86,325.194$ & 16 & $/$ & $/$ \\
\hline
\end{tabular}

The results of variance analysis and range analysis show that laser power and processing speed have significant influence on the effect of MCR frequency modulation, while the laser frequency has no significant influence. Combined with the requirements of over-frequency rate, processing time and appearance in the actual processing process, the optimal combination of laser control parameters for MCR frequency modulation are determined as A1, B4 and C1, as listed in Table 13.

Table 13. Optimal selection of laser control parameters.

\begin{tabular}{ccc}
\hline Laser Power/W & Laser Frequency/KHz & Processing Speed/(mm/s) \\
\hline 6 & 500 & 200 \\
\hline
\end{tabular}

\subsection{Experimental Verification of Laser Processing Optimal Parameters for MCR} Frequency Modulation

The optimized combination of laser processing control parameters for MCR frequency modulation are selected as the experimental parameters. The processed MCR is observed under $20 \times$ and $50 \times$ microscopes respectively, and the observation results are shown in Figure 14. It shows that the machined edge of the silver layer of the MCR electrode is relatively clean, and the black edge of the silver layer oxidation is less, which meets the requirements. 


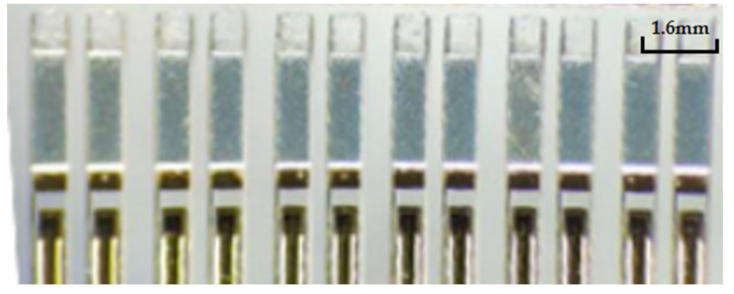

(a)

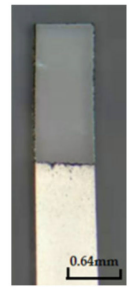

(b)

Figure 14. Results of frequency modulation processing under optimized parameters (the black edge of the silver layer oxidation is less): (a) $20 \times$ microscope observation; (b) $50 \times$ microscope observation.

30720 MCRs in 480 rows, namely, 30 slices of wafers, are processed in the verification experiments. The average frequency modulation processing time of a single-row MCR is depicted in Figure 15. The average processing completion time is 293.79 s, which is lower than the target time of $320 \mathrm{~s}$, reaching the requirements for production efficiency.

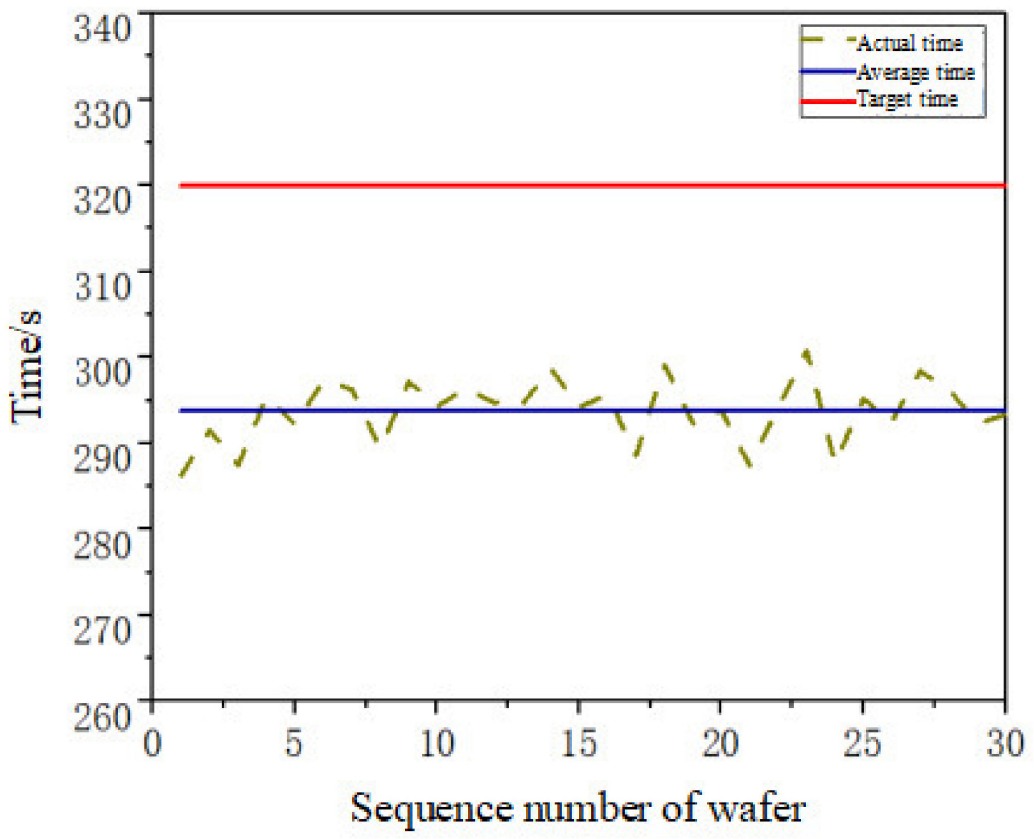

Figure 15. Frequency modulation processing time per row under optimized parameters.

The over-frequency rate of each wafer after frequency modulation is recorded and shown in Figure 16. The average defect rate is about $1.401 \%$, which is lower than the over-frequency rate index of $1.56 \%$, meeting the over-frequency rate requirements.

The amount of fault alarms of laser processing systems for MCR frequency modulation is recorded every week, and the statistical results are listed in Table 14. The fault alarm rate $\tau$ is 0.2 times per week, meeting the reliability requirements. 


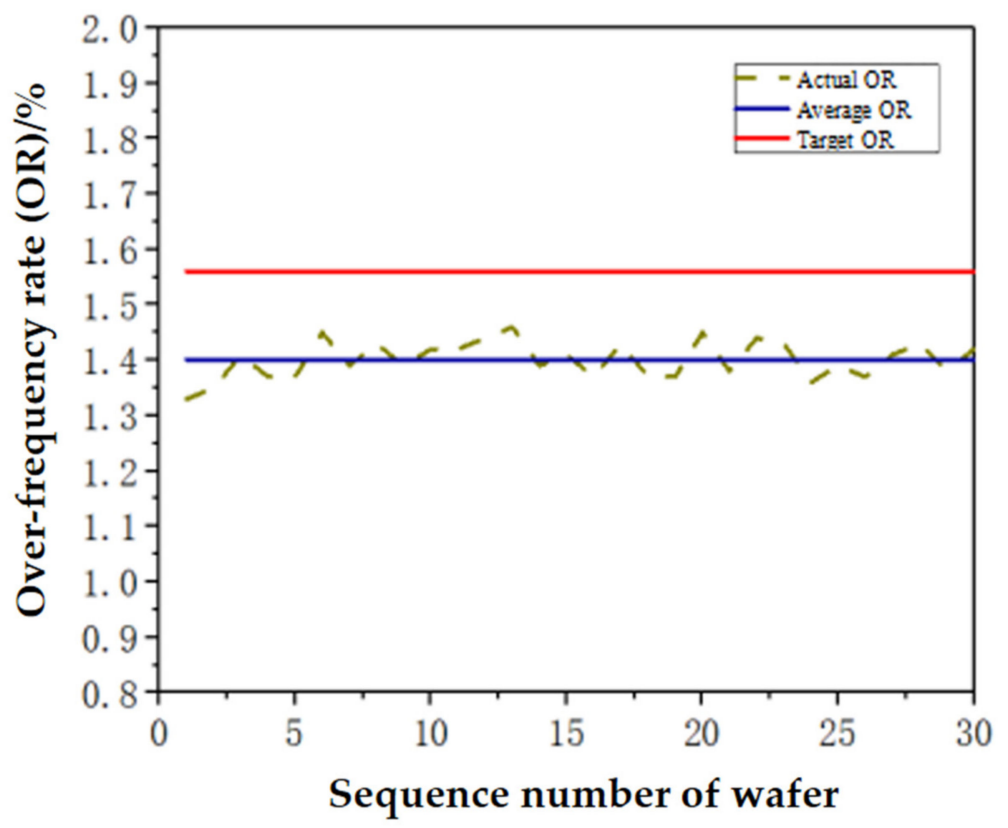

Figure 16. Over-frequency rate results under optimized parameters.

Table 14. Statistical results of system failure (number of times per week).

\begin{tabular}{cccccc}
\hline Date & $2020 / 9 / 20$ & $2020 / 9 / 27$ & $2020 / 10 / 04$ & $2020 / 10 / 11$ & $2020 / 10 / 18$ \\
Times & 1 & 0 & 0 & 1 & 0 \\
\hline Date & $2020 / 10 / 25$ & $2020 / 11 / 1$ & $2020 / 11 / 08$ & $2020 / 11 / 15$ & $2020 / 11 / 22$ \\
Times & 0 & 0 & 0 & 0 & 0 \\
\hline
\end{tabular}

\section{Conclusions}

Taking the laser processing control system for MCR frequency modulation as the research object in this paper, the performance requirements and overall structure of the control system are analyzed and designed. Based on fuzzy PID, the control method of the laser processing platform for MCR frequency modulation is proposed and developed, and the prototype function is verified. Through the experimental analysis of frequency modulation performance, the key parameters of laser processing control for MCR frequency modulation are obtained as power, frequency and processing speed. The process parameters of laser processing control for MCR frequency modulation are optimized by an orthogonal experiment, and the control system is verified to meet the actual needs of efficiency, over-frequency rate and reliability. In order to deal with the unqualified products after frequency modulation, the unqualified products will be automatically eliminated through an automatic screening method in subsequent studies to further improve the automation level of MCR production.

Author Contributions: Formal analysis, G.L.; project administration, X.Y.; resources, B.F.; supervision, Z.G.; writing-original draft, S.G.; writing-review \& editing, J.H. All authors have read and agreed to the published version of the manuscript.

Funding: This research received no external funding.

Conflicts of Interest: The authors declare no conflict of interest.

\section{References}

1. Yu, X.; Chen, X.; Ding, X.; Zhao, X. A High-Stability Quartz Crystal Resonator Humidity Sensor Based on Tuning Capacitor. IEEE Trans. Instrum. Meas. 2018, 67, 715-721. [CrossRef]

2. Elgaard, C.; Sundstrom, L. A $491.52 \mathrm{MHz} 840 \mathrm{uW}$ crystal oscillator in 28nm FD-SOI CMOS for 5G applications. In Proceedings of the European Conference on Solid-State Circuits, Leuven, Belgium, 11-14 September 2017. 
3. Ho, C.P.; Li, B.; Danner, A.J.; Lee, C. Design and modeling of 2-D photonic crystals based hexagonal triple-nano-ring resonators as biosensors. Microsyst. Technol. 2013, 19, 53-60. [CrossRef]

4. Zhang, J.-L.; Liao, S.; Chen, C.; Yang, X.-T.; Lin, S.-A.; Tan, F.; Li, B.; Wang, W.-W.; Zhong, Z.-X.; Zeng, G.-G. Research on Trimming Frequency-Increasing Technology for Quartz Crystal Resonator Using Laser Etching. Micromachines 2021, 12, 894. [CrossRef] [PubMed]

5. Shiono, T.; Osada, Y.; Nakagawa, Y. Frequency Change of Quartz Crystal Resonator Caused during Ion Beam Etching. Jpn. J. Appl. Phys. 2007, 46, 4647-4651. [CrossRef]

6. Qiang, C. Quartz Crystal Frequency Trimming Technology Based on Ion Etching. J. Suzhou Vocat. Univ. 2011, 22, 34-36.

7. Jingyu, S. Research on Frequency Trimming of Quartz Crystal Resonators by Laser Etching. Master's Thesis, Zhejiang University, Hangzhou, China, May 2008.

8. Qiang, L. Laser Frequency Trimming of Quartz Crystal Oscillators. CJVST 2010, 30, 425-429.

9. Junejo, M.; Kalhoro, A.N.; Kumari, A. Fuzzy logic based PID auto tuning method for QNET 2.0 VTOL. IJITCS 2020, 12, 9-16. [CrossRef]

10. Aruna, R.; Christa, S.J. Modeling. System identification and design of fuzzy PID controller for discharge dynamics of metal hydride hydrogen storage bed. Int. J. Hydrog. 2020, 45, 4703-4719. [CrossRef]

11. Khodadadi, H.; Ghadiri, H. Fuzzy Logic Self-Tuning PID Controller Design for Ball Mill Grinding Circuits Using an Improved Disturbance Observer. Mining. Met. Explor. 2019, 36, 1075-1090. [CrossRef]

12. Li, Q. Control System Realization of Automatic Parallel Seam Welder Based on C\# and Motion Control Card. Sci-Tech Innov. Product. 2019, 04, 70-73.

13. Xiaofeng, X. The Kinematics Analysis and Control SystemDesign of Planar Parallel Positioning Platform. Master's Thesis, China University of Mining and Technology, Xuzhou, China, May 2016.

14. Gao, G.; Zhu, Y.; Duan, G.; Zhang, M. Femtosecond laser two-photon microfabrication control and monitoring system based on virtual instruments. In Proceedings of the 2006 International Technology and Innovation Conference, Hangzhou, China, 6-7 November 2006.

15. Döring, S.; Richter, S.; Tünnermann, A.; Nolte, S. Evolution of hole depth and shape in ultrashort pulse deep drilling in silicon. Appl. Phys. A 2011, 105, 69-74. [CrossRef]

16. Brügmann, M.H.; Feurer, T. Comparative theoretical analysis of continuous wave laser cutting of metals at 1 and $10 \mu \mathrm{m}$ wavelength. Appl. Phys. A 2014, 116, 1353-1364. [CrossRef]

17. Zhang, H.; Peng, Y.; Hou, H. Research on laser cutting technology of aluminum alloy. Technol. Wind 2014, 13, 57.

18. Li, R. $\mathrm{CO}_{2}$ Laser Cutting of Thick Low-Carbon Steel. Master's Thesis, Huazhong University of Science \& Technology, Wuhan, China, May 2013.

19. Zhang, W.; Li, G.; Wang, C. Process Optimization and Design of Fiber Laser Cutting Aluminium-Lithium Alloy. Chin. J. Lasers 2015, 42, 93-99.

20. Yumei, L.; Gangyan, L.; Jian, H.; Xiaohua, H. Research on action sequence optimization method of Micro-Crystal resonator spot welding device. Ferroelectrics 2020, 565, 164-172. [CrossRef]

21. Wang, Y. Research on Control System of Linear Motor XY Table. Master's Thesis, School of Electrical Engineering Southeast University, Nanking, China, June 2016.

22. Tomizuka, M.; Hu, J.-S.; Chiu, T.-C.; Kamano, T. Synchronization of two motion control axes under adaptive feedforward control. J. Dyn. Sys. Meas. Control. 1992, 114, 196-203. [CrossRef]

23. Xiong, W.; Hao, L.; Li, Y.; Tang, D.; Cui, Q.; Feng, Z.; Yan, C. Effect of selective laser melting parameters on morphology, microstructure, densification and mechanical properties of supersaturated silver alloy. Mater. Des. 2019, 170, 107697. [CrossRef] 